\title{
BMJ Open Use of neuropsychological tests for the diagnosis of dementia: a survey of Italian memory clinics
}

\author{
Alessandra Di Pucchio, ${ }^{1}$ Nicola Vanacore, ${ }^{1}$ Fabrizio Marzolini, ${ }^{1}$ Eleonora Lacorte, ${ }^{1}$ \\ Teresa Di Fiandra, ${ }^{2}$ I-DemObs Group, Marina Gasparini ${ }^{3}$
}

To cite: Di Pucchio A, Vanacore N, Marzolini F, et al. Use of neuropsychological tests for the diagnosis of dementia: a survey of Italian memory clinics. BMJ Open 2018;8:e017847. doi:10.1136/ bmjopen-2017-017847

- Prepublication history and additional material for this paper are available online. To view these files, please visit the journal (http://dx.doi.org/10. 1136/bmjopen-2017-017847)

Received 16 June 2017 Revised 25 November 2017 Accepted 27 November 2017

\section{Check for updates}

${ }^{1}$ National Centre for Disease Prevention and Health Promotion, National Institutes of Health, Rome, Italy

${ }^{2}$ Direction of Prevention, Ministry of Health, Rome, Italy

${ }^{3}$ Department of Neurology and Psychiatry, Sapienza University, Rome, Italy

Correspondence to Dr Alessandra Di Pucchio; alessandra.dipucchio@iss.it

\section{ABSTRACT}

Aim Providing an overview of the neuropsychological tests used in Italian memory clinics (defined as Centers for Cognitive Disorders and Dementias-CCDD in Italy) for the diagnosis of cognitive disorders and dementias.

Methods A total of 501 CCDD, out of all 536 active CCDD, were surveyed between February 2014 and August 2015 to verify the characteristics of the centres who performed a comprehensive neuropsychological assessment (NPA), defined as the administration of at least one test for verbal and visual episodic memory, attention, constructional praxis, verbal fluency and executive functions (minimum core tests-MCTs), as part of the diagnostic process. Results A total of $45.7 \%$ of Italian CCDD performed a comprehensive MCT as part of the diagnostic process. The logistic regression model showed that the probability of including at least one psychologist in the team was higher in the CCDD that reported using a comprehensive NPA (OR 4.55; $95 \% \mathrm{Cl} 2.92$ to 7.1 ), that CCDD in Southern Italy had a lower probability of using an MCT (OR $0.56 ; 95 \% \mathrm{Cl}$ 0.35 to 0.89 ) and that the use of an MCT was higher in university/Institute for Scientific Research and Healthcare CCDD (OR 10.97; 95\% Cl 3.85 to 31.25 ).

Conclusion Almost half of the CCDD administered a set of MCTs; while the remaining centres only performed few tests or screening procedures. The neuropsychological tests used in Italian CCDD were comparable with those used in other European countries. Performing a comprehensive NPA remains the best way to assess and monitor cognitive deficits over time, thus further debate on the current status of NPAs in clinical practice is needed.

\section{INTRODUCTION}

Cognitive testing is consistently considered as extremely relevant in the diagnosis and follow-up of patients with dementia.

International guidelines ${ }^{1}{ }^{2}$ specifically address its use in addition to clinical investigation-the so-called incremental validity. ${ }^{3}$ A neuropsychological assessment (NPA) is aimed at defining the severity of dementia, but also at confirming a diagnostic hypothesis. Once dementia is diagnosed, a simple 'omnibus' test (eg, Mini-Mental State Examination-MMSE and Milan Overall Dementia Assessment-MODA) can provide

\section{Strengths and limitations of this study}

The main strength of this survey is the inclusion of a large and representative number of Italian memory clinics (defined as Centers for Cognitive Disorders and Dementias -CCDD in Italy) based on the whole national territory.

- The study provides an overview of the frequency of use and the availability of neuropsychological assessment and can be of support in understanding the functioning of Italian CCDDand the type of NP tools used in clinical practice to assess people with cognitive complaints.

- A limitation of the study is its being based on data from self-reported questionnaires, administered to health professionals in charge of enrolled CCDDs which could potentially over- estimate the actual scenario.

a deterioration score, which is useful for the clinical monitoring over time. ${ }^{4}$

However, in case of patients with subtle cognitive complaints but maintaining normal daily life activities, possible preclinical impairments can only be detected through a comprehensive NPA. The specific tool to be chosen in each case can vary (for a review, see Ngo and Holroyd-Leduc ${ }^{5}$ ), but it should always be proven to have strong psychometric properties.

Several attempts were made, over the years, to harmonise and uniform cognitive assessment in dementia. The Consortium to Establish a Registry for Alzheimer's Disease (CERAD) was created in 1986 by the National Institute of Aging (NIA) to standardise the procedures for the evaluation and diagnosis of patients with Alzheimer's disease (AD). The neuropsychological battery proposed by CERAD includes tests for verbal fluency and naming, the MMSE, word list recall and recognition, constructional praxis and recall of constructional praxis. The word list recall test, in particular, was found to be the best in distinguishing between patients with $\mathrm{AD}$ and healthy controls. ${ }^{6}$ In 2009, the AD Center 
Table 1 Recommendations for neuropsychological assessment for dementia

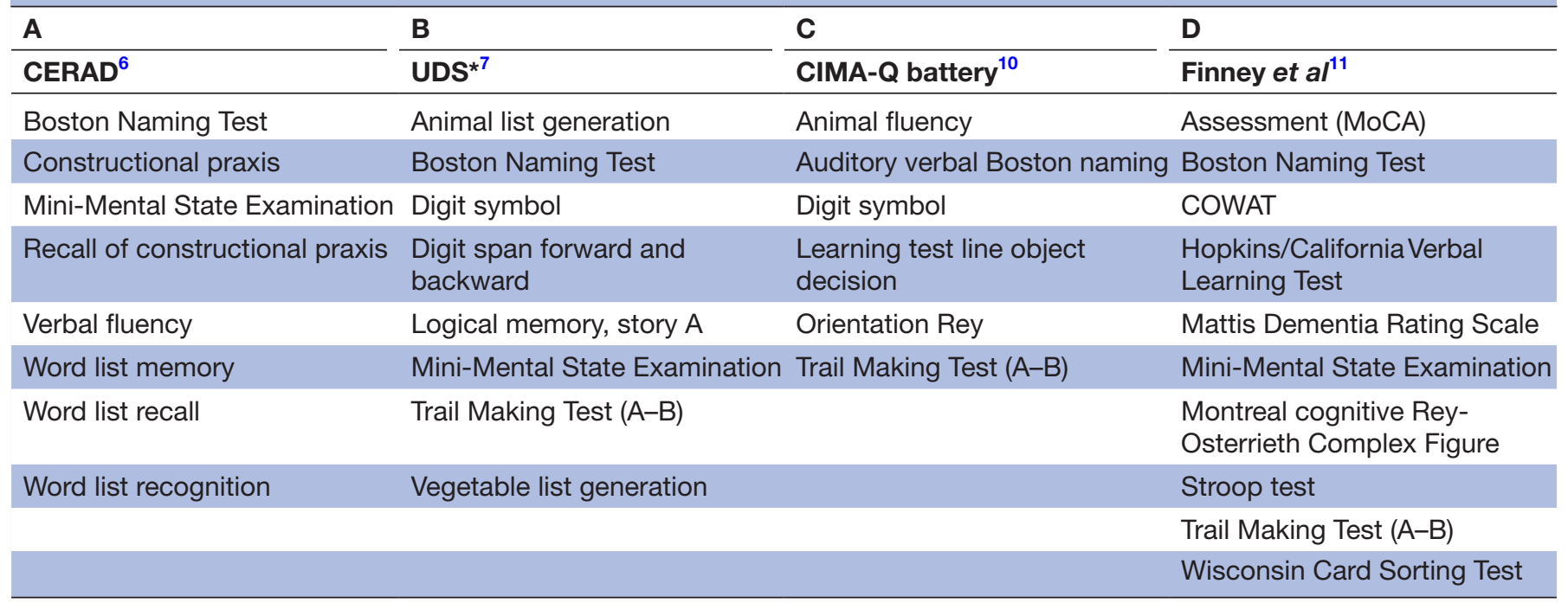

*Low sensitivity $(73.6 \%)$ and specificity $(70.8 \%)$ for $\mathrm{MCl}$.

CERAD, Consortium to Establish a Registry for Alzheimer's Disease; CIMA-Q, Consortium for the early identification of AD-Quebec; COWAT, Controlled Oral Word Association Test; MCI, Mild Cognitive Impairment; MoCA, Montreal Cognitive Assessment; UDS, uniform data set.

(ADC) programme of the NIA carried out a survey to gather data on assessment practices, including tools for the evaluation of the cognitive domain. The study designed a brief cognitive battery, to be used in ADCs. ${ }^{7}$ However, as the authors pointed out, the battery resulted as appropriate for a first evaluation, but it did not prove as an adequate substitute for a comprehensive NPA. Moreover, it did not result as an adequate tool to detect subtle impairments as compared with the CERAD battery. ${ }^{8}$

As for Europe, the European Federation of Neurological Societies task force performed a survey on the neuropsychological tests used to detect dementia in 25 countries, with the objective of harmonising their use across these countries. ${ }^{9}$ The survey identified 213 different tools, pointing out that not all of them were validated in each country. Specifically, 18-21 countries reported using verbal memory tests, but only the tests used in 11-14 of these countries were validated. These findings highlighted the critical issue of the psychometric solidity of the tools used in clinical practice and their reliability. It also underlined a difficulty in selecting which tests are to be used for the assessment and diagnosis of dementia, due to differences in the cultural context, in clinical and research practice and in healthcare policies.

Further recommendations were recently proposed for a comprehensive NPA, ${ }^{1011}$ as it may work as a good predictor of progression from subtle impairments to AD. These recommendations pointed out the need of exploring the major cognitive domains-episodic memory, constructional praxis, attention, verbal fluency and executive functions (table 1).

\section{The Italian scenario}

Italy is structured in 18 regions and two self-administered provinces, and its National Health System (NHS) is organised at national, regional and local levels. At a national level, the Ministry of Health, supported by several specialised agencies, establishes the basic principles and objectives of the health system, defines the core health services to be guaranteed across the country and distributes to each region its quote of national funds. Regions are substantial self-administered in defining the structure of their local health systems and are responsible for organising and delivering healthcare. At a local level, public and community health services and primary care are directly delivered by local health authorities (Aziende Sanitarie Locali - ASLs), whereas secondary and specialised care is either directly delivered by ASLs or accessible through public hospitals or accredited private structures.

The diagnosis, treatment and support of people with dementia within the Italian NHS are currently managed by different health and social health services. Memory clinics are defined, within the Italian NHS, as Centers for Cognitive Disorders and Dementias (CCDD) and can be based in public, territorial, outpatient services, hospitals or university hospitals or Institute for Scientific Research and Healthcare (ISRH). The team of healthcare professionals involved in these centres includes neurologists, geriatricians and psychiatrists, and financial support is provided by the NHS. CCDD are specifically dedicated to the assessment, diagnosis and management of dementias and are entitled to prescribe specific pharmacological treatments for $\mathrm{AD}$ (ie, donepezil, rivastigmine, galantamine and memantine) and/or behavioural and psychological symptoms of dementia (ie, antipsychotic drugs) based on the diagnosis and the treatment plan. In 2000, a first survey of all Italian CCDD was performed within the Cronos study, a project implemented by the Italian Ministry of Health and the Italian National Institute of Health, that identified about 500 memory clinics in Italy. ${ }^{12}$ 
Table 2 Most frequently used neuropsychological tests, batteries and clinical scales in Italy

\begin{tabular}{|c|c|}
\hline \multirow[t]{2}{*}{ A } & B \\
\hline & Italian normative studies \\
\hline \multicolumn{2}{|l|}{ Test or battery } \\
\hline Digit span & Orsini et al, $1987^{32}$ \\
\hline Corsi spatial span & Orsini et al, $1987^{32}$ \\
\hline Babcock short-tale & Carlesimo et al, $2002^{33}$ \\
\hline Rey 15-word & Carlesimo et al, $1996^{34}$ \\
\hline $\mathrm{RCF}$ & Carlesimo et al, $2002^{33}$ \\
\hline Attentional matrices & Spinnler and Tognoni, $1987^{22}$ \\
\hline Stroop test & Caffarra et al, $2002^{35}$ \\
\hline TMT & Giovagnoli et al, $1996^{36}$ \\
\hline FAB & Appollonio et al, $2005^{37}$ \\
\hline MCST & Caffarra et al, $2004^{38}$ \\
\hline FAS & Carlesimo et al, $1996^{34}$ \\
\hline Semantic word fluency test & Novelli et al, $1986^{39}$ \\
\hline Visual naming & Sartori and Job, $1988^{40}$ \\
\hline AAT & Luzzatti et al, $1996^{41}$ \\
\hline Clock drawing & Mondini et al, $2003^{42}$ \\
\hline Drawings copy & Carlesimo et al, $2002^{33}$ \\
\hline Orofacial apraxia & Spinnler and Tognoni, $1987^{22}$ \\
\hline Ideomotor apraxia & Spinnler and Tognoni, $1987^{22}$ \\
\hline CPM & Carlesimo et al, $1996^{34}$ \\
\hline SPM & Caffarra et al, $2003^{43}$ \\
\hline $\begin{array}{l}\text { Mini-Mental State } \\
\text { Examination }\end{array}$ & Measso et al, $1993^{44}$ \\
\hline MODA & Brazzelli et al, $1994^{45}$ \\
\hline MDB & Carlesimo et al, $1996^{34}$ \\
\hline ADAS & Fioravanti et al, $1994^{46}$ \\
\hline
\end{tabular}

Clinical and Behavioural

Scales

\begin{tabular}{ll} 
ADL & Katz, $1963^{47}$ \\
IADL & Lawton and Brody, $1969^{48}$ \\
GDS & Yesavage et al, $1983^{49}$ \\
FBI & Alberici et al, $2007^{50}$ \\
Insight Scale & Ott et al, 1996 \\
NPI & Cummings et al, $1994^{52}$ \\
\hline
\end{tabular}

AAT, Aachener Aphasia naming test; ADAS, Alzheimer's Disease Assessment Scale; ADL, Activities of Daily Living; CPM, Coloured Progressive Matrices; FAB, Frontal Assessment Battery; FAS, Phonemic word fluency test; FBI, Frontal Behavioural Inventory; GDS, Geriatric Depression Scale; IADL, Instrumental Activities of Daily Living; MCST, Modified Wisconsin Card Sorting Test; MDB, Mental Deterioration Battery; MODA, Milan Overall Dementia Assessment; NPI, Neuropsychiatric Inventory; RCF, Rey Complex Figure; SPM, Standard Progressive Matrices; TMT, Trail Making Test.

Two more surveys, one performed in 2002 and the second in 2006, aimed at identifying and characterising the activities carried out by memory clinics. Their objective was to acknowledge the importance of the role of memory clinics in the diagnosis and treatment of people with dementia, but also to assess the wide variability in their distribution and characteristics at a regional and local level. ${ }^{13} 14$

The 2002 survey showed a wide variability between memory clinics, in both the type of cognitive tests adopted and their use. About $50 \%$ of memory clinics declared to perform an NPA, but such a percentage was probably overestimated due to an unclear definition of 'what' an NPA should actually be. The Alzheimer's Disease Assessment Scale-cognitive subscale (ADAS-cog) resulted to be the most frequently used tool, despite it being proven as useful for the monitoring, but not for the diagnosis of dementia. On the other hand, only $5.6 \%-18 \%$ of the structures reported using a test for episodic memory, attention and/or language. The study highlighted two main issues: (1) a higher probability of misdiagnosis in the memory clinics that did not use an NPA and (2) a need to improve the psychometric properties of some of the adopted tools. In 2008, Bianchi and Dai Prà ${ }^{15}$ published a review of all Italian normative studies published from 1987 to 2007 and provided new standards to choose the best tools to be used in clinical practice. The results of the review support the use of short batteries to test patients with advanced dementia and to administer a core assessment of episodic memory to subjects in the preclinical stages of the disease.

The Italian 'National Dementia Plan' (NDP), in 2014, redefined the existing memory clinics renaming them as CCDD, but maintaining their central role in the network of healthcare and social care services and recognising the need to reorganise services for dementia in integrated care pathways. ${ }^{16}$ The Italian National Institute of Health (INIH) actively participated in the development of the NDP and was also entrusted, within the 2013 programme of research actions of the National Centre for Disease Prevention and Control, funded by the Italian Ministry of Health, with the management of the national project: 'Survey of the social and health services dedicated to dementias and creation of a specific website: Observatory for dementias'.

A new survey was conducted in $2015,{ }^{17}$ as part of this project. The methodology and methodological issues of the survey are reported in a dedicate publication. ${ }^{17}$

This study had the objective of describing the use of neuropsychological tests for the diagnosis of cognitive disorders and dementia within the Italian CCDD and to investigate the possible relationship between the use of these tests and the presence or absence of a psychologist in the multidisciplinary teams working in CCDD.

\section{MATERIALS AND METHODS Surveyed services}

A total of 536 CCDD were surveyed from February 2014 to August 2015 at a national level. The methodology used to carry out the survey of all health and social services currently available in Italy for people with dementia is reported in a dedicated paper. ${ }^{17} \mathrm{~A}$ list of all CCDD was obtained contacting designed representatives from each 
Table 3 Distribution of the CCDD included in the survey according to type and geographical distribution

\begin{tabular}{|c|c|c|c|c|}
\hline \multirow[b]{3}{*}{ Type of CCDD } & B & $\mathbf{C}$ & D & E \\
\hline & \multicolumn{4}{|c|}{ Geographical distribution } \\
\hline & Northern Italy n (\%) & Central Italy n (\%) & Southern Italy $\mathbf{n}(\%)$ & Total n (\%) \\
\hline Hospital & $148(67.6)$ & $43(49.4)$ & 75 (38.5) & 266 (53.1) \\
\hline Territorial services & $53(24.2)$ & $31(35.6)$ & $112(57.4)$ & $196(39.1)$ \\
\hline University/ISRH & $18(8.2)$ & $13(14.9)$ & $8(4.1)$ & $39(7.8)$ \\
\hline Total & $219(43.7)$ & $87(17.4)$ & $195(38.9)$ & $501(100)$ \\
\hline
\end{tabular}

CCDD, Centre for Cognitive Disorders and Dementias; ISRH, Institute for Scientific Research and Healthcare.

region, as these structures are heterogeneously distributed across the territory. ${ }^{17}$

The survey was included in action 1.2 of the objective 1 of the Italian national plan of dementia. ${ }^{16}$ No ethical approval or informed consent was used as all respondents were public institutions, and all questions were about services' activities.

\section{Survey questionnaire}

A standardised form, designed to identify structure, process and outcome indicators, was used to gather information on the type of NPA tools and the clinical scales, tests and batteries used in CCDD, for the diagnosis and assessment of dementias.

Information on the presence of a psychologist in the staff, on the type of service (eg, part of a hospital, territorial or university structure or an ISRH), on the overall percentage of patients assisted per year and on the proportion of patients who receive a comprehensive NPA was also included.

The questionnaire was administered to all health professionals in charge of enrolled CCDD. The completed forms were collected through a specifically designed online platform, and data were exported for statistical analyses (see online supplementary data).

\section{Minimum core tests}

Neuropsychological tests were classified according to the cognitive and functional domains they investigated. Based on compendia of cognitive testing ${ }^{1819}$ and the recommendations from the Italian Neuropsychological Society (INS), ${ }^{20}$ the following categories were defined: (1) screening test, (2) batteries for global assessment, (3) tests for memory, attention, executive functions, constructional abilities and (4) emotional status and behaviour. Naming tests were categorised separately from semantic fluency tests, due to their validation studies being of low quality.

To verify the use of a comprehensive NPA in the diagnosis of cognitive disorders and dementia, we identified a minimum core test (MCT). We defined as MCT an essential set of tests for the evaluation of the main cognitive functions, including at least one test for each of the following cognitive domains: both verbal and visual episodic memory, attention, constructional praxis, verbal fluency and executive functions. A set of test meeting these requirements, in fact, according to the compendia and the recommendations from the Italian Neuropsychological Society (INS), ${ }^{18}{ }^{19}$ would allow a CCDD to detect both the presence of subtle cognitive impairments and different patterns of dementia.

All tests, batteries and clinical scales that are currently validated in the Italian population were listed and included in the survey questionnaire with the objective of collecting data on the neuropsychological tests routinely used in Italian CCDD for the diagnosis of dementias (table 2).

\section{Statistical analysis}

The frequency of the use of neuropsychological tests for the diagnosis of dementia was calculated and reported as percentages. A $\mathrm{X}^{2}$ test was used to compare the number of services reporting the use of MCT.

A regression logistic model was also designed to assess the association between the use of a minimum core of neuropsychological tests, the geographical distribution and type of CCDD and the presence of at least one psychologist in the staff. ORs and their 95\% CIs were calculated within the model. $\mathrm{P}$ values lower than $0.05(5 \%)$ were considered as statistically significant. All statistical analyses were carried out using the Statistical Package for the Social Sciences (SPSS V.23.0).

\section{RESULTS}

A total of $501(93.5 \%)$ centres returned the completed forms: 219 (43.7\%) from Northern Italy, 87 (17.4\%) from Central Italy and 195 (38.9\%) from Southern Italy and the islands. The response rate resulted similar across the different areas. The geographical distribution and type of CCDD are reported in table 3.

Table 4 reports data on the use of NP tools in Italian CCDD. The results from the present survey (2015) were also compared with the results from the 2002 survey.

A total of 229 (45.7\%) of the included CCDD reported using a comprehensive NPA for the diagnosis of dementia, meeting the criteria for the MCT (table 5).

Of the 229 CCDD that reported using an MCT, 81.7\% included a psychologist in the team (table 5). The majority of services that used an MCT were based in Northern Italy $(55.5 \%)$ and were hospital services $(60.3 \%)$, whereas the lower frequency of services using an MCT was reported in Southern Italy and the Islands (25.3\%) (table 5). 
Table 4 Comparison between the neuropsychological tests used in Italian CCDD based on the results from two different surveys

\begin{tabular}{|c|c|c|}
\hline A & B & C \\
\hline & $\begin{array}{l}\text { Tests in use during } \\
\text { the } 2002 \text { survey }{ }^{1314}\end{array}$ & $\begin{array}{l}\text { Tests in use } \\
\text { during the current } \\
\text { survey }\end{array}$ \\
\hline Domains-functions/test & $\%$ & $\%$ \\
\hline \multicolumn{3}{|l|}{ Memory } \\
\hline Rey 15-words & 11 & 65 \\
\hline Babcock short-tale & 11.2 & 69.6 \\
\hline RCF recall & - & 52.2 \\
\hline Corsi spatial span & 12 & 46.4 \\
\hline Digit span & 4.8 & 52.8 \\
\hline Visual memory & 1.3 & - \\
\hline \multicolumn{3}{|l|}{ Language } \\
\hline AAT & 1.5 & 17.8 \\
\hline Visual naming & - & 17 \\
\hline $\begin{array}{l}\text { Semantic word fluency } \\
\text { test }\end{array}$ & 15.3 & 61.2 \\
\hline Token test & 13.3 & - \\
\hline \multicolumn{3}{|l|}{ Constructional abilities } \\
\hline Drawings copy & - & 52.4 \\
\hline RCF-copy & 5.6 & 55.4 \\
\hline Clock drawing & 9.7 & 83.6 \\
\hline \multicolumn{3}{|l|}{ Attention } \\
\hline Stroop test & 2.3 & 33.2 \\
\hline TMT-A & 1.3 & 51.6 \\
\hline Attentional matrices & 18.4 & 54.4 \\
\hline \multicolumn{3}{|l|}{ Executive functions } \\
\hline SPM & 6.1 & 41.4 \\
\hline CPM & 1.3 & 33.2 \\
\hline MCST & 0.3 & 24.2 \\
\hline TMT-B & 1.3 & 51.6 \\
\hline FAS & 17.1 & 61.8 \\
\hline \multicolumn{3}{|l|}{$\begin{array}{l}\text { Clinical and Behavioural } \\
\text { Scales }\end{array}$} \\
\hline ADAS-cog & 24 & 2.4 \\
\hline MDB & - & 22.6 \\
\hline MODA & 23.5 & 29.8 \\
\hline WAIS-R & 3.1 & - \\
\hline MoCA & - & 6.6 \\
\hline
\end{tabular}

AAT, Aachener Aphasia naming test; ADAS-cog, Alzheimer's Disease Assessment Scale-cognitive subscale; CCDD, Centre for Cognitive Disorders and Dementias; CPM, Coloured Progressive Matrices; FAS, Phonemic word fluency test; MCST, Modified Wisconsin Card Sorting Test; MDB, Mental Deterioration Battery; MoCA, Montreal Cognitive Assessment; MODA, Milan Overall Dementia Assessment; RCF, Rey Complex Figure; SPM, Standard Progressive Matrices; TMT, Trail Making Test; WAIS-R, Wechsler Adult Intelligence Scale-Revised.

The logistic regression model showed that the probability of including at least one psychologist in the team was higher in the CCDD that reported using a comprehensive
Table 5 Geographical distribution, type of structure and presence of at least a psychologist in the CCDD that used and did not use a minimum core set of neuropsychological tests

\begin{tabular}{|c|c|c|c|}
\hline \multirow[t]{3}{*}{ A } & B & C & \multirow{3}{*}{$\begin{array}{l}\text { D } \\
\text { P value }\end{array}$} \\
\hline & \multicolumn{2}{|c|}{$\begin{array}{l}\text { Use of a minimum core } \\
\text { set of neuropsychological } \\
\text { tests }\end{array}$} & \\
\hline & $\begin{array}{l}\text { Yes }(n=229) \\
(\%)\end{array}$ & $\begin{array}{l}\text { No }(n=272) \\
(\%)\end{array}$ & \\
\hline \multicolumn{4}{|l|}{$\begin{array}{l}\text { Geographical } \\
\text { distribution of CCDD }\end{array}$} \\
\hline Northern Italy & $127(55.5)$ & $92(33.8)$ & \\
\hline Central Italy & 44 (19.2) & $43(15.8)$ & 0.001 \\
\hline $\begin{array}{l}\text { Southern Italy and } \\
\text { Islands }\end{array}$ & $58(25.3)$ & $137(50.4)$ & \\
\hline \multicolumn{4}{|l|}{ Type of CCDD } \\
\hline Territorial services & 57 (24.9) & $139(51.1)$ & \\
\hline Hospital & $138(60.3)$ & $128(47.1)$ & 0.001 \\
\hline University/ISRH & $34(14.8)$ & $5(1.8)$ & \\
\hline $\begin{array}{l}\text { Psychologist (at least } \\
\text { one) }\end{array}$ & $187(81.7)$ & $119(43.8)$ & 0.001 \\
\hline
\end{tabular}

CCDD, Centre for Cognitive Disorders and Dementias; ISRH, Institute for Scientific Research and Healthcare.

NPA (OR 4.55; 95\% CI 2.92 to 7.1). The model also showed that CCDD in Southern Italy had a lower probability of using an MCT (OR 0.56 ; 95\% CI 0.35 to 0.89 ) and that the probability of using an MCT was higher in

Table 6 Logistic regression model showing the association between the use of a minimum core of neuropsychological tests in CCDD and their geographical distribution and type and the presence of at least one psychologist in the staff

\begin{tabular}{|c|c|c|c|c|}
\hline \multirow[t]{3}{*}{ A } & \multirow[t]{2}{*}{ B } & C & D & \multirow[t]{2}{*}{$\mathbf{E}$} \\
\hline & & \multicolumn{2}{|l|}{$95 \% \mathrm{Cl}$} & \\
\hline & OR & Lower & Upper & $P$ value \\
\hline \multicolumn{5}{|c|}{ Psychologist (at least one) } \\
\hline Not & 1.00 & & & \\
\hline Yes & 4.55 & 2.91 & 7.10 & 0.001 \\
\hline
\end{tabular}

Geographical distribution

of CCDD

\begin{tabular}{lrlrl}
\hline Northern Italy & 1.00 & & & \\
\hline Central Italy & 1.13 & 0.63 & 2.02 & 0.685 \\
\hline Southern Italy_Islands & 0.56 & 0.35 & 0.89 & 0.014 \\
\hline $\begin{array}{l}\text { Type of CCDD } \\
\text { Territorial services }\end{array}$ & 1.00 & & & \\
Hospital & 1.96 & 1.28 & 3.02 & 0.002 \\
University/IRCSS & 10.97 & 3.85 & 31.25 & 0.001 \\
\hline
\end{tabular}

CCDD, Centre for Cognitive Disorders and Dementias; IRCSS,

Institute for Scientific Research and Healthcare. 
university/ISRH CCDD (OR 10.97; 95\% CI 3.85 to 31.25 ) (table 6).

\section{DISCUSSION AND CONCLUSION}

The present survey provides an overview of the use and the availability of NPA in Italian CCDD. Some previous studies gathered information on the tools used to assess and diagnose dementia, but they either included a limited number of centres ${ }^{21}$ or involved only representatives of national neurological associations. ${ }^{9}$ Our study specifically focused on healthcare centres that directly manage people with dementia with the objective of describing the approach to cognitive testing in patients with dementia within the public national health system.

The first, relevant finding was a considerable difference between the 2002 survey and this survey in both the type of tools adopted and their use. Some of the tools were used much more sporadically due to either their low sensitivity (eg, visual memory) or their inadequacy in identifying dementia (Wechsler Adult Intelligence Scale-Revised). Some other tools, instead, are now considerably less widespread (eg, ADAS-cog) as they were introduced in clinical practice due to their diffusion as an outcome measure in clinical trials on cholinesterase inhibitors. On the other hand, a considerable increase was observed in the use of some key tools for the early diagnosis of dementia, such as tests for episodic memory, phonemic and semantic fluency, executive functions and constructional abilities.

This might be explained by a progressive increase in the number of available cognitive tests between the year 1987, when the Study of Standardisation by Spinnler and Tognoni ${ }^{22}$ was published and the year 2000, when the Italian memory clinics were created. About 49 studies were carried out during these 13 years and 64 in the following 10 years. This caused a progressive shifting from 'historical' tests (eg, the WAIS scales) to new tests specifically designed to target the demographical changes of the population, and the trend is still ongoing (see Barletta-Rodolfi $e t a l^{20}$ ).

When comparing results from this survey with data from other European countries, ${ }^{9}$ no substantial differences were observed in the type of tests used. All cognitive domains resulted to be assessed in a quite homogeneous way, despite a degree of variability in some tools (eg, in language and verbal memory). However, two specificities emerged. First, the tests aimed at assessing abstract thinking (eg, Raven's Progressive Matrices) resulted as widely used in Italy, while their use seemed to be much less frequent in other European countries. Second, all tests used in Italian structures were validated on the Italian population and thus resulted as having good psychometric properties.

Results from the survey showed also that the majority of CCDD administering an MCT included at least a psychologist in the team. About $46 \%$ of the centres offered an MCT, with significant differences between the centres in Northern Italy and the centres in Central and Southern Italy. The CCDD in Northern Italy seemed to have a better profile, whereas the CCDD in Central and Southern Italy seemed to have similar organisational characteristics. The importance of including an operator specifically trained to administer NPA tools was first highlighted in 1985, when the American Psychological Association defined and detailed the required standards for neuropsychological examiners. ${ }^{23}$ Italy included these requirements within the expertise of professional psychologists (1. 56/89; DM 24/7/2006). However, uncertainties still exist on who can do what. Moreover, any health professional who administer NP tests should be specifically trained, and a constant interaction between neuroanatomical specialties and cognitive and clinical psychology should be maintained when interpreting the results from any type of NP test.

Results from the present survey also showed that more than half of the included CCDD based their screening procedures mainly on the administration of rough cognitive (eg, MMSE) and functional (eg, Activities of Daily Living and Instrumental Activities of Daily Living) scales or a small set of tests. This lack of expertise raises the issue of what is an NPA and what is it thought to be.

The knowledge on the clinical manifestations of AD considerably increased starting from 1984, when the National Institute of Neurological and Communicative Disorders and Stroke-Alzheimer's Disease and Related Disorders Association (NINCDS-ADRDA) criteria for the diagnosis of probable AD were established. ${ }^{24}$

The NINCDS-ADRDA criteria were then revised by the NIA,$^{25}$ due to the need to clearly discriminate $\mathrm{AD}$ from either other conditions leading to dementia (eg, frontotemporal dementia and primary progressive aphasia) or non-amnestic forms of $\mathrm{AD}$. The core clinical criteria for a diagnosis of all-cause dementia require the presence of cognitive or behavioural symptoms involving at least two cognitive domains among memory, judgement, visuospatial abilities, language and behaviour. The new criteria to define a diagnosis of probable $\mathrm{AD}$ also require an either amnestic or non-amnestic significant initial cognitive deficit and, in case of a non-amnestic $\mathrm{AD}$, concomitant linguistic, visuospatial and executive dysfunctions.

Therefore, the NPA needs to quantify the deficit, but also to define a pattern of scores that can provide a diagnostic clue on the possible aetiology, considering that cognitive functions depend on neural network involving different brain areas. ${ }^{26}$

A recent review highlighted that mild cognitive impairments may be undetected by simple mental status examination and brief screening tests. ${ }^{27}{ }^{28}$ Short cognitive tests, however, are still widespread in clinical practice, in particular in countries where healthcare policies are defined based on their cost-effectiveness and specifically, on the costs of tools and instruments, 
the time needed to administer them and the costs related to misdiagnoses (false positives and/or false negatives).

This kind of tests is currently being promoted by some international programmes to optimise the cognitive screening in primary care,${ }^{29}{ }^{30}$ where the prevalence of undiagnosed cases is high. ${ }^{4}$ However, CCDD, that are designed as second-level/third-level referral units, should use this type of tests as part of the clinical examination and in the monitoring over time of already diagnosed patients, rather than adopt them as diagnostic tools, considering their intrinsic limitations (for a review, see Brown $^{31}$ ). A comprehensive NPA, thus, is currently the best way to assess and quantify cognitive deficits ${ }^{26}$ and should be the minimum requirement for the diagnosis of dementia.

The main strength of this survey is the inclusion of structures based on the whole national territory. This study can be of support in understanding the functioning of Italian CCDD and the type of NP tools used in clinical practice to assess people with cognitive complaints.

This is an extremely relevant issue, considering also that potentially disease-modifying treatments are currently under development, that will require more sensitive neuropsychological measures for the early identification of cognitive disorders and dementia.

The main limitation of this survey is its being based on self-administered questionnaires, thus potentially overestimating the scenario. The misuse of NP tests could prevent a homogeneity in the evaluation criteria and the comparability of data from different CCDD.

The number and type of tests used in the diagnostic process of dementia should follow recommendations from the Italian Neuropsychological Society included in the national guidelines, thus closing the gap between cognitive neurosciences and public health.

The external validity of our results refers to all Italian CCDD (501 out of all the 536 active CCDD were surveyed). This information can also be useful to compare the use of neuropsychological tests between memory clinics from different countries.

Acknowledgements Special thanks to our colleagues in the contacted facilities for responding to the survey.

Collaborators I-DemObs Group (Italian Dementia Observatory Group): Ilaria Bacigalupo (IB); Monica Bolli (MB), Marco Canevelli (MC); Patrizia Carbonari (PC), Annamaria Confaloni (AC); Alessio Crestini (ACr); Flavia Mayer (FMa); Luana Penna (LP), Paola Piscopo (PP)

Contributors All authors contributed extensively to the work presented in this paper. ADP contributed to the conception and design of the study, acquisition and interpretation of data and drafting the manuscript. FM and EL contributed to the acquisition of data and revising it critically. TDF contributed to the conception of the study and revising it critically. MG contributed to the design of the study, interpretation of data and writing the manuscript. IB, MB, MC, PC, AC, ACr, FMa, LP and PP (in the I-DemObs Group) contributed to the acquisition of data and giving technical support and conceptual advice. NV is the principal investigator of the project that provided financial support for the paper and contributed to the conception and design of the study, analysis and interpretation of data and critically revising the manuscript. All authors gave final approval of the version to be published and agreed to be accountable for all aspects of the work.
Funding The study was supported by grants from the Italian Ministry of HealthNational Center for Disease Prevention and Control (2013 programme of research actions - central actions).

Competing interests None declared.

Patient consent Not required.

Provenance and peer review Not commissioned; externally peer reviewed.

Data sharing statement No additional data are available.

Open Access This is an Open Access article distributed in accordance with the Creative Commons Attribution Non Commercial (CC BY-NC 4.0) license, which permits others to distribute, remix, adapt, build upon this work non-commercially, and license their derivative works on different terms, provided the original work is properly cited and the use is non-commercial. See: http://creativecommons.org/ licenses/by-nc/4.0/

(C) Article author(s) (or their employer(s) unless otherwise stated in the text of the article) 2018. All rights reserved. No commercial use is permitted unless otherwise expressly granted.

\section{REFERENCES}

1. Hort J, O'Brien JT, Gainotti G, et al. EFNS guidelines for the diagnosis and management of Alzheimers disease. Eur $J$ Neurol 2010;17:E839-42.

2. Sorbi S, Hort J, Erkinjuntti T, et al. EFNS-ENS guidelines on the diagnosis and management of disorders associated with dementia. Eur J Neurol 2012;19:1159-79.

3. Haynes SN, Lench HC. Incremental validity of new clinical assessment measures. Psychol Assess 2003;15:456-66.

4. Lin JS, OConnor E, Rossom RC, et al. Screening for cognitive impairment in older adults: a systematic review for the U.S. preventive services task force. Ann Intern Med 2013;159:601-12.

5. Ngo J, Holroyd-Leduc JM. Systematic review of recent dementia practice guidelines. Age Ageing 2015;44:25-33.

6. Morris JC, Heyman A, Mohs RC, et al. The Consortium to Establish a Registry for Alzheimers Disease (CERAD). Part I. Clinical and neuropsychological assessment of alzheimer's disease. Neurology 1989;39:1159-65.

7. Weintraub S, Salmon D, Mercaldo N, et al. The Alzheimers Disease Centers uniform Data Set (UDS): the neuropsychologic test battery. Alzheimer Dis Assoc Disord 2009;23:91-101.

8. Mathews M, Abner E, Kryscio R, et al. Diagnostic accuracy and practice effects in the national alzheimers coordinating center uniform data set neuropsychological battery. Alzheimers Dement 2014;10:675-83.

9. Maruta C, Guerreiro M, de Mendonça A, et al. The use of neuropsychological tests across Europe: the need for a consensus in the use of assessment tools for dementia. Eur $J$ Neurol 2011:18:279-85.

10. Belleville S, Fouquet C, Duchesne S, et al. Detecting early preclinical alzheimer's disease via cognition, neuropsychiatry, and neuroimaging: qualitative review and recommendations for testing. $J$ Alzheimers Dis 2014;42(Suppl 4):S375-82.

11. Finney GR, Minagar A, Heilman KM. Assessment of mental status. Neurol Clin 2016:34:1-16.

12. Raschetti R, Maggini M, Sorrentino GC, et al. A cohort study of effectiveness of acetylcholinesterase inhibitors in alzheimer's disease. Eur J Clin Pharmacol 2005;61:361-8.

13. Sorrentino GC, Caffari B, Vanacore N, et al. [The characteristics of alzheimer's disease units in relation to neuropsychological tests]. Ann Ist Super Sanita 2005;41:63-8.

14. Bianchi G, Gasparini M, Caffari B, et al. L'uso degli strumenti neuropsicologici nell'ambito del Progetto Cronos.[Use of neuropsychological tests in the Cronos Project]. Ann Ist Super Sanita 2005;41:69-74.

15. Bianchi $A$, Dai Prà M. Twenty years after Spinnler and Tognoni: new instruments in the Italian neuropsychologists toolbox. Neurol Sci 2008;29:209-17.

16. Di Fiandra T, Canevelli M, Di Pucchio A, et al. The Italian dementia national plan. Commentary. Ann Ist Super Sanita 2015;51:261-4.

17. Di Pucchio A, Di Fiandra T, Marzolini F, et al. Survey of health and social-health services for people with dementia: methodology of the Italian national project. Ann Ist Super Sanita 2017;53:246-52.

18. Lezak M, Howieson D, Loring D. Neuropsychological assessment. New York: Oxford University Press, 2004.

19. Strauss $\mathrm{E}$, Sherman $\mathrm{E}$, Spreen O. A compendium of neuropsychological tests. New York: Oxford University Press, 2006. 
20. Barletta-Rodolfi C, Gasparini F, Ghidoni E. Kit del neuropsicologo italiano. Milano: Dynamicon, 2011.

21. Paulino Ramirez Diaz S, Gil Gregório P, Manuel Ribera Casado J, et al. The need for a consensus in the use of assessment tools for alzheimer's disease: the Feasibility Study (assessment tools for dementia in Alzheimer Centres across Europe), a European Alzheimer's Disease Consortium's (EADC) survey. Int J Geriatr Psychiatry 2005;20:744-8.

22. Spinnler H, Tognoni G. Standardizzazione e taratura Italiana di test Neuropsicologici. Ital J Neurol Sci 1987;6:25-7.

23. American Psychological Association. Standards for educational and psychological testing. Washington DC: American Psychological Association, 1985

24. McKhann G, Drachman D, Folstein M, et al. Clinical diagnosis of Alzheimer's disease: report of the NINCDS-ADRDA Work Group under the auspices of Department of Health and Human Services Task Force on Alzheimer's Disease. Neurology 1984;34:939-44.

25. McKhann GM, Knopman DS, Chertkow H, et al. The diagnosis of dementia due to Alzheimer's disease: recommendations from the National Institute on Aging-Alzheimer's Association workgroups on diagnostic guidelines for Alzheimers disease. Alzheimers Dement 2011;7:263-9.

26. Burrell JR, Piguet O. Lifting the veil: how to use clinical neuropsychology to assess dementia. J Neurol Neurosurg Psychiatry 2015;86:1216-24.

27. Allan CL, Behrman S, Ebmeier KP, et al. Diagnosing early cognitive decline-When, how and for whom? Maturitas 2017;96:103-8.

28. Lu PH, Lee GJ. The role of neuropsychology in the assessment of the cognitively impaired elderly. Neurol Clin 2017;35:191-206.

29. NHS commissioning board, 2013. http://www.england.nhs.uk/ wp-content/uploads/2013/03/ess-dementia.pdf (accessed 15 May 2017)

30. Borson S, Frank L, Bayley PJ, et al. Improving dementia care: the role of screening and detection of cognitive impairment. Alzheimers Dement 2013;9:151-9.

31. Brown J. The use and misuse of short cognitive tests in the diagnosis of dementia. J Neurol Neurosurg Psychiatry 2015;86:680-5.

32. Orsini A, Grossi D, Capitani E, et al. Verbal and spatial immediate memory span: normative data from 1355 adults and 1112 children. Ital J Neurol Sci 1987;8:537-48.

33. Carlesimo GA, Buccione I, Fadda L, et al. Standardizzazione di due test di memoria per uso clinico. Breve racconto e figura di Rey. Nuova Riv Neurol 2002;12:1-13.

34. Carlesimo GA, Caltagirone C, Gainotti G, et al. The mental deterioration battery: normative data, diagnostic reliability and qualitative analyses of cognitive impairment. Eur Neurol 1996;36:378-84.

35. Caffarra P, Vezzadin G, Dieci F, et al. Una versione abbreviata del test di Stroop: dati normativi nella popolazione italiana. Nuova Rivista di Neurologia 2002;12:111-5.
36. Giovagnoli AR, Del Pesce M, Mascheroni S, et al. Trail making test: normative values from 287 normal adult controls. Ital J Neurol Sci 1996;17:305-9.

37. Appollonio I, Leone M, Isella V, et al. The Frontal Assessment Battery (FAB): normative values in an Italian population sample. Neurol Sci 2005;26:108-16.

38. Caffarra P, Vezzadini G, Dieci F, et al. Modified card sorting test: normative data. J Clin Exp Neuropsychol 2004;26:246-50.

39. Novelli G, Papagno C, Capitani E, et al. Tre test clinici di ricerca e produzione lessicale. Taratura su soggetti normali. Arch Psicol Neurol Psichiatr 1986;4:477-506.

40. Sartori G, Job R. The oyster with four legs: a neuropsychological study on the interaction of visual and semantic information. Cogn Neuropsychol 1988;5:105-32.

41. Luzzatti C, Willmes K, De Bleser R. Aachener apahsie test: versione italiana (II edizione. Firenze: Organizzazioni Speciali, 1996.

42. Mondini S, Mapelli D, Vestri A, et al. Una batteria di test per lo screening neuropsicologico. Milano: Esame Neuropsicologico Breve (ENB), 2003.

43. Caffarra P, Vezzadini G, Zonato F, et al. A normative study of a shorter version of Ravens progressive matrices 1938. Neurol Sci 2003;24:336-9.

44. Measso G, Cavarzeran F, Zappalà G, et al. The mini-mental state examination: Normative study of an Italian random sample. Dev Neuropsychol 1993;9:77-85.

45. Brazzelli M, Capitani E, Della Sala S, et al. MODA, milan overall dementia assessment. Firenze: Giunti O.S, 1994.

46. Fioravanti $M$, Nacca $D$, Buckley $A E$, et al. The Italian version of the Alzheimers Disease Assessment Scale (ADAS): psychometric and normative characteristics from a normal aged population. Arch Gerontol Geriatr 1994;19:21-30.

47. Katz S, Ford AB, Moskowitz RW, et al. Studies of illness in the aged. the index of adl: a standardized measure of biological and psychosocial function. JAMA 1963;185:914-9.

48. Lawton MP, Brody EM. Assessment of older people: selfmaintaining and instrumental activities of daily living. Gerontologist 1969;9:179-86.

49. Yesavage JA, Brink TL, Rose TL, Lum O, et al. Development and validation of a geriatric depression screening scale: a preliminary report. J Psychiatr Res 1983;17:37-49.

50. Alberici A, Geroldi C, Cotelli M, et al. The frontal behavioural inventory (italian version) differentiates frontotemporal lobar degeneration variants from alzheimers disease. Neurol Sci 2007;28:80-6.

51. Ott BR, Lafleche G, Whelihan WM, et al. Impaired awareness of deficits in alzheimer disease. Alzheimer Dis Assoc Disord 1996;10:68-76.

52. Cummings JL, Mega M, Gray K, et al. The neuropsychiatric inventory: comprehensive assessment of psychopathology in dementia. Neurology 1994;44:2308-14. 